\title{
Old age expectations are related to how long people want to live
}

\author{
CATHERINE E. BOWEN* and VEGARD SKIRBEKK††
}

\begin{abstract}
How long do people want to live? Why do some people want to live a very long time, and others would rather die relatively young? In the current study we examine the extent to which the preference to die young $(<8$ o years, less than average life expectancy) or to live somewhat longer or much longer than average life expectancy (90-99 years or $100+$ years, respectively) is related to a person's positive and negative expectations of what their life will be like in old age. We use multinomial regression analysis based on survey data from a large sample of younger and middle-aged adults in the United States of America (USA) ( $\mathrm{N}=1,631$, age 18-64 years). We statistically control for socio-demographic characteristics as well as self-reported happiness and health. We find that having fewer positive expectations for their own old age distinguishes people who prefer to die relatively young, while having fewer negative expectations distinguishes people who want to live beyond current levels of life expectancy. The results provide evidence that pessimistic expectations of life in old age can undermine the desire to live up to and beyond current average life expectancy. The study also provides descriptive data about how young and middle-aged adults in the USA anticipate their own ageing.
\end{abstract}

$\boldsymbol{K E Y} \boldsymbol{W} \boldsymbol{O R D S}$ - longevity, preferred life expectancy, old age expectations, desired lifetime, subjective ageing.

\section{Introduction}

How long do people want to live? In 1 975, an average 6o-year-old woman living in a high-income country could expect to live to about age 80 given prevailing period mortality rates. By 2015 , she could expect to live to about age 85 (United Nations, Department of Economic and Social Affairs, Population Division 2015). Life expectancy especially at older ages is expected to continue to increase in the coming decades (United Nations, Department of Economic

* Wittgenstein Centre for Demography and Global Human Capital, Vienna Institute of Demography/Austrian Academy of Sciences, Austria.

$\dagger$ Norwegian Institute of Public Health, Oslo, Norway.

* The Robert N. Butler Columbia Aging Center, Columbia University, New York, USA. 
and Social Affairs, Population Division 2015). The historical increase in life expectancy is widely regarded as one of the most important human achievements of the modern era, but the few available studies on longevity preferences suggest that not everyone welcomes the prospect of a longer life. In fact, studies and surveys have revealed that people differ quite a bit with regards to their preferred life expectancy (PLE) (American Association of Retired Persons (AARP) 2006, 2010; Huohvanainen et al. 2012; Karppinen et al. 2012; Lang, Baltes and Wagner 2007; Pew Research Center 2009, 2013). Available data suggest that a significant minority of people would prefer to die relatively young, before reaching current levels of average life expectancy. For instance, in a representative sample of American 65 -year-old adults, more than twice the number of participants expressed a desire to die before 80 than to live 100 years or longer ( $13 \%$ versus $5 \%$; AARP 2010). For comparison, at the time of the survey the average life expectancy of 65 -year-olds in the United States of America (USA) was approximately 85 years (Social Security Administration n.d.). Importantly, at least two previous studies have demonstrated that PLE predicts actual mortality (Huohvanainen et al. 2012; Karpinnen et al. 2012). In other words, there is a significant and meaningful relationship between how long people want to live and how long they actually live. It is therefore highly relevant to understand why some people want to live a very long time, and some people would prefer to die young.

What might distinguish people who prefer to die young from those who want to live a very long life? When people think about how long they want to live, one thing they might think about is the extent to which living into the eighties, nineties or beyond represents more of a blessing or a curse. Studies on subjective representations of old age have demonstrated that people vary widely with regards to their expectations of the ageing process and old age. In the current study, we therefore investigated whether how long people prefer to live is related to their subjective expectations about what their own life in old age will be like. We expected that people with more negative and fewer positive expectations for their own life in old age would be more likely to prefer to die young than to grow old. We base our analyses on a large sample $\left(\mathrm{N}=1,63_{1}\right)$ of younger and middle-aged adults in the USA. Since few studies have explored how younger adults think about their own ageing, we also explored the descriptive characteristics of younger adults' longevity preferences and their positive and negative old age expectations.

\section{Individual differences in PLE}

The desire to avoid death and prolong life are assumed to be powerful and universal human instincts (Becker 1973; Freud 1920). At the same time that 
self-preservation is assumed to be a universal human characteristic, there are also abundant anecdotal examples of individuals who demonstrate an extraordinarily strong desire to continue life even in the face of the most hopeless life conditions, and at the other extreme, individuals that demonstrate an exceptionally low desire to continue living by committing suicide. Indeed, as noted by Vernon (1972), the fear of living under certain conditions may sometimes be stronger than the fear of death. Empirical research on constructs from psychology, public health and economics such as the valuation of life (Lawton et al. 1999, 2001), the will to live (e.g. Carmel 2001; Carmel, Shrira and Shmotkin 2013), death attitudes such as death acceptance and fear of death (e.g. Wong, Reker and Gesser 1994), public attitudes towards the hypothetical prospect of general life extension due to medical and technological advances (e.g. Dragojlovic 2013) and preferences for length versus quality of life using 'time trade-off' tasks (e.g. Ayalon and King-Kallimanis 2010) have confirmed that there are substantial differences in the extent to which people wish to extend their own lives as well as fear and/or strive to avoid their own death. In the current paper, we take an 'individual differences' approach to try to identify factors that lie behind why some people indicate a desire to live a very long time, while other people indicate a desire to die relatively young.

Almost 4o years ago, Richard Kalish and David Reynolds (1976) published the results of a rich and multifaceted study on death attitudes amongst a community sample of $\mathrm{N}=438$ adults representative of Los Angeles county in the USA. As part of the study, the authors assessed how long people wanted to live, providing, to our knowledge, the first empirical evidence on PLE. Since then, a handful of published empirical studies and surveys have assessed how long people want to live (AARP 2006, 2010; Huohvanainen et al. 2012; Karppinen et al. 2012; Lang, Baltes and Wagner 2007; Pew Research Center 2009, 2013). There has also been empirical research on a number of other attitudes about longevity and death (e.g. valuation of life, will to live, death attitudes and death anxiety, public attitudes towards life extension, time trade-off tasks in which people indicate how many life years in imperfect health they would be willing to exchange for life years in perfect health). Empirical research on PLE and these related constructs has generally not, however, focused on individual differences that is, why one person has more positive attitudes about longevity while another person has rather negative attitudes. Nevertheless, previous studies offer information about how a handful of personal characteristics, including socio-demographic characteristics (age, gender, socio-economic status, race), health and wellbeing are related to how a person thinks and feels about longevity. In the following, we summarise how these personal characteristics are thought to be and/or have been empirically associated 
with individual differences in PLE and related constructs as a starting point for the current study.

Age

In studies including older adults $\left(65^{+}\right)$, older people consistently report wanting to live to a somewhat older age than younger people (Huohvanainen et al. 2012; Kalish and Reynolds 1976; Lang, Baltes and Wagner 2007; Pew Research Center 2013). It is unclear, however, whether the relationship between age and PLE is linear; that is, if older age is likewise associated with the preference for longer lives amongst younger and middle-aged adults. Studies on death attitudes provide some clues of how age may be related to PLE specifically amongst younger and middle-aged adults. In a cross-sectional study with a lifespan sample (18-87), death anxiety was highest amongst people in their twenties (Russac et al. 2007). Thus, there is at least some suggestion that younger adults may be more likely to indicate a preference for a very long life due to their fear of death, though not all studies have found evidence that young and middle-aged adults differ with regards to their death attitudes (Wong, Reker and Gesser 1994).

\section{Gender}

Studies have consistently indicated that women are generally less positive towards the prospect of living longer. In the study by Kalish and Reynolds (1976), for example, men reported wanting to live longer than women across all age groups (20-39 years, 40-59 years and 6o+ years). Women are also more likely to indicate a preference for shorter but healthier lives as opposed to longer lives in less than perfect health (Ayalon and KingKallimanis 2010). Women have also been found to report a lower will to live (Carmel 2001; Carmel, Shrira and Shmotkin 2013) as well as less desire to prolong life by medical interventions in hypothetical health conditions (Carmel 2001), and also express less support for an extension of average life expectancy to 120 years (Dragojlovic 2013) relative to men. Thus, despite the fact that women tend to live longer than men, and that the public seems to be aware of this difference (O'Connell 2011), the evidence suggests that women are likely to report a younger PLE than men.

\section{Socio-economic status}

People with higher education and higher income tend to live longer and have a higher quality of life relative to their peers (Elo 2009; Kibele, Jasilionis and Shkolnikov 2013; Knesebeck et al. 2007; Olshansky et al. 
2012), which may likewise result in preferences to live longer. People with higher income presumably also have more financial resources for coping with age-related losses which would thus seem to be related to a preference for longer lives. However, despite the consistent relationships between indicators of socio-economic status and actual longevity, previous research has not found consistent relationships between indicators of socio-economic status and longevity preferences. For instance, previous studies have not found evidence that PLE was related to education (Lang, Baltes and Wagner 2007; Pew Research Center 2013). People with higher education also tend to indicate a preference for shorter but healthier lives as opposed to longer lives in less than perfect health (Ayalon and KingKallimanis 2010). Furthermore, education has no clear relationship with support for moderate extensions to average life expectancy (Dragojlovic 2013). Income was not related to PLE among German adults (Lang, Baltes and Wagner 2007). However, financial resources may be more important for longevity preferences in the USA relative to Germany due to different health and welfare systems. At this point, it is thus unclear how socioeconomic status (indicated by education and income) is related to PLE.

\section{Race}

Several studies have confirmed that longevity-related attitudes are also related to race, at least in the USA. For instance, Kalish and Reynolds (1976) found that Black Americans had the oldest PLE, followed by Japanese, White and Mexican Americans (with PLEs of 88.6, 80.1, 79.7 and 75.8 years, respectively). Racial and ethnic minorities tend to prefer and pursue more aggressive end-of-life care relative to Caucasian Americans, even after statistically controlling for a number of potentially confounding socio-cultural variables (Barnato et al. 2009). Likewise, racial and ethnic minorities tend to indicate a preference for longer lives in ill health in time trade-off tasks (Ayalon and King-Kallimanis 2010). In sum, previous research suggests that Black/African-American race is related to older PLE.

\section{Health and wellbeing}

People who feel healthier and/or happier report wanting to live longer (Huohvanainen et al. 2012; Lang, Baltes and Wagner 2007) and indicate a higher valuation of life (Jopp, Rott and Oswald 2008). Prior research has also shown that there are moderate to strong positive associations between the will-to-live and measures of mental health in community samples (Carmel 2001; Carmel, Shrira and Shmotkin 2013). Likewise, people with worse subjective health tend to indicate a greater preference for shorter but healthier lives (Ayalon and King-Kallimanis 2010). 
Together, the results of previous studies suggest that better health and wellbeing is related to older PLE.

The results of the empirical studies summarised above provide some clues about the factors that distinguish people who want to live a very long time from people who would prefer to die relatively young. The available empirical evidence suggests that some socio-demographic variables (i.e. age, gender and race, but not education or income) as well as selfrated health and wellbeing explain some variation in people's attitudes towards longevity and death. Specifically, older age, male gender, Black/ African-American race, and better health and wellbeing all seem to be related to the desire to live a longer life. While the results of previous studies offer an important starting point for research on individual differences in PLE, to date research has been largely atheoretical and descriptive as opposed to explanatory. In the current study, we therefore build on this initial research to investigate one factor we believe to be related to how long people want to live - namely people's expectations about what their own life in old age will be like.

\section{Longevity preferences and old age expectations}

Key to the current study is that at the same time that there seem to be some characteristics more or less universally associated with older people and the ageing process in general (e.g. high warmth, low competence, Cuddy, Norton and Fiske 2005; overall negative attitude, Kite et al. 2005; age-related gains and losses, Heckhausen, Dixon and Baltes 1989), individuals also vary widely in the extent to which they expect their own ageing process and old age to be characterised by positive and negative changes and circumstances. For instance, people vary in the extent to which they experience and anticipate their own ageing as a process of ongoing personal development, physical decline and changes in social status (Steverink et al. 2001). Research has shown that people have multiple and distinct representations of old age which vary across life domains such as health, family and work (Kornadt and Rothermund 2011). Previous research has also robustly demonstrated that people have both negative and positive old age representations. Importantly, having negative representations about old age and ageing (e.g. with regards to changes in health) does not preclude also having positive representations about old age and ageing (e.g. with regards to opportunities for continuous development) (Steverink et al. 2001). For instance, the same person may associate old age with illness, but may also think about old age as a time for enjoying a 'late freedom' (Rosenmayr 1983), financial security and being able to travel (Pew Research Center 2013). 
Notably, individual differences in how people perceive and anticipate their own ageing explain systematic variation in health, health behaviours and even survival years later (for a meta-analysis of longitudinal studies, see Westerhof et al. 2014). Initial evidence suggests that a person's mental representations of old age are also related to his or her longevity preferences. Levy, Ashman and Dror (2000) showed in a small-scale experimental study ( $\mathrm{N}=32$ older adults and $\mathrm{N}=32$ younger adults) that older people subliminally exposed to positive old age stereotypes indicated a stronger preference for hypothetical life-prolonging medical treatments, no matter what the treatment cost or how much of a burden the treatment would be for their family members. In contrast, older adults exposed to negative old age stereotypes tended to refuse the same treatments, even though the scenarios mentioned that without the treatments they would likely die within a month (Levy, Ashman and Dror 2000). The results of the study from Levy, Ashman and Dror (2000) were recently replicated with a Portuguese sample $(\mathrm{N}=54$ older adults and $\mathrm{N}=61$ younger adults; Marques et al. 2014). In a larger longitudinal study $(\mathrm{N}=660)$, older participants who perceived their own ageing more positively at baseline also perceived life in retirement as more full, hopeful and worthy - an indirect measure of longevity preferences - two years later. In turn, people who perceived life in retirement as more full, hopeful and worthy lived longer than their peers (Levy et al. 2002).

Together, the results of the three studies described above provide some evidence that mental representations of old age, whether experimentally manipulated or chronically accessible, are related to people's longevity preferences. We build on this initial evidence by investigating whether perceptions of one's own ageing are related to PLE in a large and heterogeneous sample of younger and middle-aged adults. We hypothesised that people who expect that their life in old age will be characterised by more losses and negative events (e.g. health problems, memory problems, decrease in sexual activity) will tend to prefer to die younger. We likewise hypothesised that people who expect that their life in old age will be characterised by more gains, new opportunities and/or maintained functioning (e.g. more time to devote to hobbies and interests, getting involved in the community, financial security) will tend to want to live longer lives.

\section{Age as a moderator of the relationship between old age expectations and longevity preferences}

In the current study we were also interested in investigating potential age differences in the relationship between old age expectations and longevity 
preferences. On the one hand, subjective representations of old age are more self-relevant at older relative to younger ages (e.g. Levy 20o9; Kornadt and Rothermund 2011, 2012). That is, thoughts about old age become more personally meaningful as one starts to identify as 'old'. In turn, how people think and feel about their own ageing are generally thought to affect older people more than younger people. For instance, in the experimental study by Levy, Ashman and Dror (200o) cited earlier, only older people's preferences for hypothetical life-saving medical interventions were affected by their exposure to subliminal reminders of positive and negative old age stereotypes. In contrast, younger adults' preferences for treatment were not affected by the experimental manipulation (Levy, Ashman and Dror 2000). In the current context, one might therefore expect that the relationship between longevity preferences and old age expectations would be stronger at mid-life relative to younger adulthood.

On the other hand, however, social cognitive research has also demonstrated that people tend to rely more upon schematic beliefs when making judgements about events far in the future (Trope and Liberman 2010). Because old age and death are psychologically further away for younger relative to middle-aged adults, one might also expect that schematic expectations of old age are more strongly related to the longevity preferences of younger people. Research on affective forecasting errors also bears relevance for our consideration of how the relationship between longevity preferences and old age expectations might depend on age. A large body of experimental work has demonstrated that although people are rarely wrong about whether future events will make them feel good or bad, they are frequently mistaken about just how good or bad that feeling will be (for a review, see Wilson and Gilbert 2005). Specifically, people tend to overestimate the effect that future negative or positive events would have on their future wellbeing. Interestingly, there is also some evidence that younger adults are particularly prone to making such errors (Nielsen, Knutson and Carstensen 2008). In the current context, one might therefore expect that especially younger adults overestimate how age-related gains and losses would affect their desire to live. In light of these two contrasting rationales, we did not have a set hypothesis with regards to how the relationship between PLE and old age expectations would differ based on age.

\section{Current study}

The current study is one of the first empirical investigations of individual differences in longevity preferences - that is, why one person wants to live 
longer than another person. We were particularly interested in whether how long people want to live would be related to their expectations about what their life in old age will be like. We based our analyses on data from a large, heterogeneous sample of young and middle-aged adults in the USA. We used multivariate regression analysis to test whether negative and positive old age expectations were related to PLE. We statistically controlled for the personal characteristics shown and/or postulated to be associated with PLE and other indicators of longevity preferences in previous studies as described above: age, gender, education, income, race/ethnicity, health and happiness. Finally, we explored whether the relationship between negative and positive old age expectations and PLE depended on participants' age.

To date, few empirical studies have investigated how younger adults perceive their own ageing. We therefore were additionally interested in providing descriptive statistics about the number of positive and negative expectations for one's own old age and PLE for four theoretically meaningful age groups represented in our sample: emerging adults, young adults, early mid-life adults and late mid-life adults (Arnett 2000; Staudinger and Bluck 2001).

\section{Method}

\section{Sample and procedure}

The current study was based on a secondary analysis of data from a telephone survey of $\mathrm{N}=1,63^{1}$ younger and middle-aged adults living in the continental USA conducted by the Pew Research Center (2010). Interviews were conducted in either English or Spanish in February and March 20o9. The sampling strategy was designed to yield data representative of the adult population in the USA (for more information on sampling strategy, see Pew Research Center 2009). Unless otherwise noted, we refer to the unweighted statistics. Participants were on average 42.30 years old (standard deviation $=13 \cdot 5^{6}$, range $=18-64$ years $)$. Half $(49.8 \%)$ of the participants were women and 32.9 per cent were university graduates.

\section{Measures}

PLE. Participants were asked, 'If you had your choice, how long would you like to live? That is, until what age? (Just your best guess is fine.)'. Responses over 120 years were recoded as 120 .

Old age expectations. Participants indicated whether or not (yes/no) they expected that their own life in old age would be characterised by nine negative states (a serious illness, memory loss, being a burden, no longer sexually 
active, not being able to drive, not feeling needed, trouble paying bills, often feeling sad or depressed, loneliness) and nine positive states (travelling for pleasure, spending more time on hobbies and interests, less stress, more family time, volunteer work or community involvement, not having to work, more financial security, starting a new job or second career, more respect). We created a sum score of positive age expectations and negative age expectations (potential range: $\mathrm{O}^{-} \mathrm{9}$ ). Sum scores were assigned only to participants who answered each of the nine items.

Control variables. Participants indicated their age, gender (male/female), race/ethnicity (White, non-Hispanic/Black non-Hispanic/Hispanic/other), highest formal educational qualification $(1=$ less than high school, $2=$ high school, 3 =some college, 4 =college or more), income (ten categories ranging from $1=$ less than US $\$ 10$, ooo to $9=$ US $\$ 15$, ooo or more), subjective health $(1=$ poor, $2=$ only fair, $3=\operatorname{good}, 4=$ excellent $)$ and overall happiness (not too happy/pretty happy/very happy).

Age groups. Based on the age variable, we created four age groups: emerging adulthood $(\mathrm{N}=255 ; 18-25$ years $)$, young adulthood $\left(\mathrm{N}=45^{2} ; 26-40\right.$ years), early mid-life $\left(\mathrm{N}=453 ; 4^{1-52}\right.$ years $)$ and late mid-life $(\mathrm{N}=471$; $53-64$ years). The age groups were based on theoretically meaningful age group distinctions as described in the literature on adult development (Arnett 2000; Staudinger and Bluck 2001) and, to the extent possible, to create age groups with approximately the same number of participants so that the significance statistics (e.g. p-value; dependent on sample size) would be roughly comparable.

\section{Statistical analysis}

SPSS 20 was used to conduct all analyses. Variables with at least four answer categories were treated as continuous. Prior to analysis, we transformed the categorical variables (race/ethnicity, gender, happiness) into a series of dummy variables.

Missing data. Missing data on two variables exceeded 5 per cent: PLE $(15.9 \%)$ and income ( $11.7 \%)$. In addition, missing data on five of the negative old age expectations items exceeded 5 per cent: serious illness $(12.9 \%)$, memory loss $(7.5 \%)$, no longer sexually active $(9.0 \%)$, not able to drive $(8.4 \%)$ and trouble paying bills $(5.6 \%)$. Although missing data was relatively high across some of the negative old age expectation items, the vast majority of participants $(98.0 \%)$ answered at least five of the nine items. Substantial information on negative old age expectations was therefore available for 
nearly all participants. Missing data across all other variables and items was low $(\leqslant 5.0 \%)$. To preserve power and reduce potential bias, we used the multiple imputation procedure in SPSS to create 15 data-sets with missing data imputed. We followed the recommendations from Graham (2009) and from Gottschall, West and Enders (2012) with regards to the multiple imputations of missing data (e.g. dummy variables created for the categorical variables prior to imputation; imputation at the item level for the age expectation scale items; no rounding). We used the multiple imputed data-sets to conduct all analyses. Unless otherwise noted, we report and interpret the pooled estimates which account for uncertainty due to missing data.

PLE non-response. Because the rate of non-response on the PLE item was rather high and because it was our main variable of interest, we conducted a binary logistic regression analysis with 'response/non-response' on the PLE item as the dependent variable and all of the other study variables (age, gender, race, education, income, health, happiness, positive and negative old age expectations) as independent variables.

Descriptive analyses. To provide information about the US population of younger and middle-aged adults, we used the weighted statistics to calculate the median and distribution of PLE. We used the chi-square test to check whether the distribution of PLE varied across the four age groups. We also calculated the weighted mean number of negative and positive age expectations for each of the four age groups.

Bivariate analyses. We analysed the bivariate correlations between the predictor variables to check for potential collinearity amongst the predictor variables.

Main analyses. We wanted to test the multivariate relationships between negative age expectations (sum), positive age expectations (sum), sociodemographic variables, health, happiness and four categories of PLE: less than 80 years, 8o-89 years, 9o-99 years and 10o+ years. Ordinal regression analysis was not appropriate because the test of parallel lines was significant when PLE was treated as an ordinal variable, indicating that the slopes of the predictor variables were not uniform across outcome categories. We therefore conducted a multinomial regression analysis. In 2009 (the year of the survey), average life expectancy for 18-65-year-olds was in the eighties (Social Security Administration n.d.). We consequently used 8o-89 years as the reference category in order to test predictors of preferring to die before average life expectancy ( $<8$ o years), somewhat longer than average life expectancy (9o-99 years) or much longer than average life expectancy 
T A B LE 1. Results of the binary logistic regression analysis of preferred life expectancy non-response

\begin{tabular}{lcccc}
\hline & $B$ & SE $B$ & $p$ & Odds ratio \\
\hline Age & 0.03 & 0.01 & 0.00 & 1.03 \\
Gender (female) & -0.08 & 0.14 & 0.57 & 0.92 \\
Education & -0.01 & 0.08 & 0.93 & 0.99 \\
Income & -0.07 & 0.04 & 0.09 & 0.93 \\
Race/ethnicity: & 0.39 & 0.19 & 0.04 & 1.48 \\
$\quad$ Black & 0.85 & 0.19 & 0.00 & 2.33 \\
$\quad$ Hispanic & 0.35 & 0.29 & 0.23 & 1.42 \\
$\quad$ Other & 0.17 & 0.09 & 0.08 & 1.18 \\
Health & -0.08 & 0.16 & 0.64 & 0.93 \\
Happiness: & 0.01 & 0.20 & 0.98 & 1.01 \\
$\quad$ Very happy & -0.14 & 0.04 & 0.00 & 0.87 \\
$\quad$ Not too happy & -0.06 & 0.03 & 0.04 & 0.94 \\
Old age expectations: & -2.32 & 0.53 & 0.00 & 0.10 \\
$\quad$ Positive & $\quad$ & & & \\
Constant & & & & \\
& &
\end{tabular}

Notes: SE: standard error. The dependent variable was o (response) or 1 (non-response). Model $\chi^{2}(12)=71.19, p<0.001$.

(100+ years). In order to investigate whether the relationship between age expectations and PLE depended on age, we calculated two interactions: age $\times$ positive old age expectations and age $\times$ negative age expectations (expectation scores and age centred around the grand means). All variables were entered into the model simultaneously.

\section{Results}

\section{PLE non-response}

Table 1 displays the results of the binary logistic regression of non-response on the PLE item. Older age, Black/African-American and Hispanic race/ ethnicity, fewer positive old age expectations and fewer negative old age expectations were each associated with a higher probability of non-response on the PLE item. Although the prediction model was statistically significant, the model correctly identified less than 2 per cent of non-respondents.

\section{PLE}

Median PLE was go years (weighted). Figure 1 displays the cumulative percentage of responses (weighted) to the PLE item. Responses were grouped around the start of life decades (e.g. 80, 9o, 1 oo years). According to the weighted statistics, just under one-fifth of the respondents indicated that 


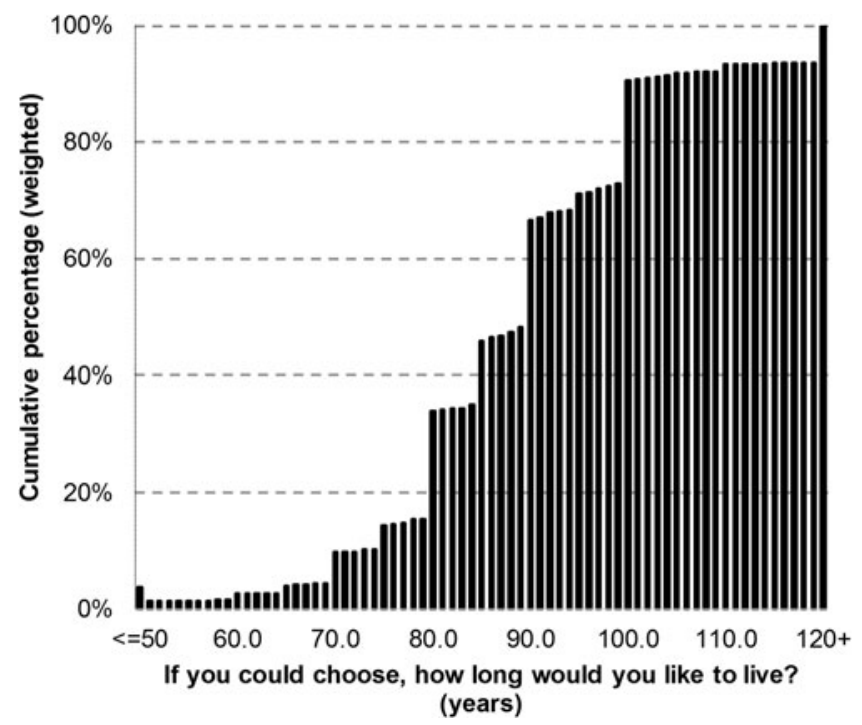

Figure 1. Distribution of responses to the preferred life expectancy item.

they preferred a life expectancy less than 80 years $(17.1 \%)$. These participants reported wanting to die younger than they are expected to live based on the average life expectancy statistics for adults between 18 and 65 (see above). Approximately one-third of the participants indicated that they would prefer a life expectancy in the eighties, or about equal to average life expectancy $(31.9 \%)$. Approximately one-quarter of participants indicated that they would prefer a life expectancy in the nineties $(24.6 \%)$, somewhat longer than average life expectancy. The rest of the participants indicated that they would prefer a life expectancy of 100 or more years $(26.4 \%)$, much longer than average life expectancy. There were no differences with regards to either the median (9o years) or the distribution of PLE across the four age groups, $\chi^{2}(9)=8.8_{3}, p=0.45$.

\section{Expectations of own old age across age groups}

The weighted mean number of positive/negative old age expectations (possible range: $\mathrm{o}^{-} 9$ ) was $6.78 / 3.23,6.57 / 2.97,6.18 / 3.49$ and $5.65 / 3.79$ for the emerging, young, early mid-life and late mid-life adults, respectively.

\section{Bivariate analyses}

Table 2 displays the means and/or frequencies as well as the bivariate relationships among the predictor variables. The highest bivariate correlation 
among the predictor variables was between income and education $(r=0.49)$. Hence, the bivariate correlations did not point to any major problem with collinearity. Also noteworthy is that the correlation between negative and positive old age expectations was low in magnitude $(r=-0.18)$, confirming that negative and positive old age expectations are only moderately related (e.g. Steverink et al. 2001$)$.

\section{Main results}

Table 3 displays the results of the multinomial regression analysis. The results confirm that the predictors were not uniformly related to the PLE response categories. Having fewer positive old age expectations was associated with the preference to die before reaching average life expectancy. Having fewer negative old expectations was associated with the preference to live either somewhat longer or much longer than average life expectancy. The age by negative old age expectations interaction was a significant predictor of the preference to live much longer than average life expectancy (100+ years).

To better understand the direction of the age by negative old age expectations interaction, we re-ran the model separately for each of the four age groups (without the age interaction terms). The relationship between negative old age expectations and preference for a life much longer than average life expectancy was significant only for participants in late middle age: early adulthood: $B=0.07$ (standard error $(\mathrm{SE})=0.08$ ), $p=0.3^{8}$; young adulthood: $B=0.00(\mathrm{SE}=0.05), p=0.95$; early mid-life: $B=-0.09(\mathrm{SE}=0.06)$, $p=0.12$; late mid-life: $B=-0.17(\mathrm{SE}=0.06), p=0.01$. In other words, with older age the preference to live much longer than average life expectancy was increasingly dependent on a person's negative old age expectations.

There was no indication that the relationship between preferring a life shorter or longer than average life expectancy depended on age, gender or education. Higher income was related to both preferring a life shorter than average life expectancy and a life much longer than average life expectancy. Black/African-American race was associated with preference for a much longer life than average life expectancy. People who identified themselves as Hispanic or as a race/ethnicity other than White/Caucasian, Black/African-American or Hispanic were more likely to indicate a preference for a life shorter than average life expectancy.

Self-rated health was not associated with preferring a life shorter than average life expectancy, but was associated with preferring a life somewhat longer or much longer than average life expectancy. Finally, 'not being too happy' was associated with preferring a shorter than average life expectancy. 
T А в L E 2. Descriptive statistics and bivariate correlations of study variables

\begin{tabular}{|c|c|c|c|c|c|c|c|c|c|c|c|c|c|c|}
\hline & & $\begin{array}{c}\text { Mean (SD) } \\
\text { or } \%\end{array}$ & 1 & 2 & 3 & 4 & 5 & 6 & 7 & 8 & 9 & 10 & 11 & 12 \\
\hline 1 & Age (18-64) & $42.30(13.56)$ & 1 & & & & & & & & & & & \\
\hline 2 & Gender (female) $(\%)$ & 49.8 & $0.07 * * \mathrm{a}$ & & & & & & & & & & & \\
\hline 3 & Education $(1-4)$ & $2.82(1.01)$ & $0.14^{* * b}$ & $0.06^{*^{\mathrm{a}}}$ & & & & & & & & & & \\
\hline 4 & Income (1-9) & $5.08\left(2.3^{6}\right)$ & $0.18^{* * b}$ & $-0.08 * *^{\mathrm{a}}$ & $0.49^{* * \mathrm{~b}}$ & & & & & & & & & \\
\hline 5 & Black (\%) & 20.3 & $0.01^{\mathrm{a}}$ & $0.05^{* c}$ & $-0.06^{* \mathrm{a}}$ & $-0.14^{* *^{\mathrm{a}}}$ & & & & & & & & \\
\hline 6 & Hispanic (\%) & 18.9 & $-0.12^{* *^{a}}$ & $0.01^{\mathrm{c}}$ & $-0.25^{* *^{\mathrm{a}}}$ & $-0.21^{* *^{a}}$ & $-0.24^{* *^{c}}$ & & & & & & & \\
\hline 7 & Other race/ethnicity (\%) & 6.9 & $-0.08 * *^{\mathrm{a}}$ & $0.03^{c}$ & $0.05^{* \mathrm{a}}$ & $0.01^{\mathrm{a}}$ & $-0.13^{* * c}$ & $-0.13^{* * c}$ & & & & & & \\
\hline 8 & Health (1-4) & 3.06 (o.83) & $-0.13^{* * \mathrm{~b}}$ & $0.00^{\mathrm{a}}$ & $0.23^{* * \mathrm{~b}}$ & $0.29^{* * b}$ & $-0.09^{* *^{\mathrm{a}}}$ & $-0.07^{* * a}$ & $-0.03^{\mathrm{a}}$ & & & & & \\
\hline 9 & Very happy $(\%)$ & 32.8 & $-0.06^{*^{\mathrm{a}}}$ & $0.03^{c}$ & $0.03^{\mathrm{a}}$ & $0.08^{* * a}$ & $-0.02^{\mathrm{c}}$ & $0.04^{\mathrm{c}}$ & $-0.08^{2 * \mathrm{c}}$ & $0.18 * *^{\mathrm{a}}$ & & & & \\
\hline 10 & Not too happy (\%) & 16.1 & $0.09 * *^{\mathrm{a}}$ & $-0.03^{\mathrm{c}}$ & $-0.15^{* *^{\mathrm{a}}}$ & $-0.19^{* *^{\mathrm{a}}}$ & $0.01^{\mathrm{c}}$ & $0.11^{* *^{c}}$ & $0.01^{c}$ & $-0.25 * *^{\mathrm{a}}$ & $-0.32^{* *^{c}}$ & & & \\
\hline 11 & Positive OAE (o-q) & $6.31(1.84)$ & $-0.19^{* * b}$ & $-0.02^{\mathrm{a}}$ & $0.01^{b}$ & $0.08 * * b$ & $0.10^{* * a}$ & $0.02^{\mathrm{a}}$ & $-0.01^{\mathrm{a}}$ & $0.18 * * \mathrm{~b}$ & $0.06 *^{\mathrm{a}}$ & $-0.15 * *^{\mathrm{a}}$ & & \\
\hline 12 & Negative OAE (o-9) & $3.41(2.72)$ & $0.07 * * \mathrm{~b}$ & $0.01^{\mathrm{a}}$ & $-0.09^{* * \mathrm{~b}}$ & $-0.10^{* * \mathrm{~b}}$ & $-0.06 * *^{\mathrm{a}}$ & $0.03^{\mathrm{a}}$ & $0.03^{\mathrm{a}}$ & $-0.26 * * b$ & $-0.14^{* *^{\mathrm{a}}}$ & $0.20^{* *^{\mathrm{a}}}$ & $-0.18 * * \mathrm{~b}$ & \\
\hline \multirow[t]{5}{*}{13} & PLE (1-4) (\%): & & $0.01^{b}$ & $0.05^{\mathrm{a}}$ & $0.04^{\mathrm{b}}$ & $0.04^{\mathrm{b}}$ & $0.20^{* *^{\mathrm{a}}}$ & $-0.08^{* * a}$ & $-0.07^{*^{\mathrm{a}}}$ & $0.13^{* * b}$ & $0.12^{* *^{\mathrm{a}}}$ & $-0.12 * *^{\mathrm{a}}$ & $0.15^{* * \mathrm{~b}}$ & $-0.17^{* * b}$ \\
\hline & $\leqslant 80$ years & 16.0 & & & & & & & & & & & & \\
\hline & $80-89$ years & 31.7 & & & & & & & & & & & & \\
\hline & 90-99 years & 22.4 & & & & & & & & & & & & \\
\hline & $100+$ years & 30.0 & & & & & & & & & & & & \\
\hline
\end{tabular}

Notes: Descriptive statistics refer to the raw, unweighted data without imputations. Correlation statistics refer to the pooled estimates. Potential value ranges are in parentheses. All of the variables were coded such that higher values indicate 'more' of the construct (e.g. education, income). We caution that the test of parallel lines indicated that the relationship between preferred life expectancy (PLE) and the study variables was not linear

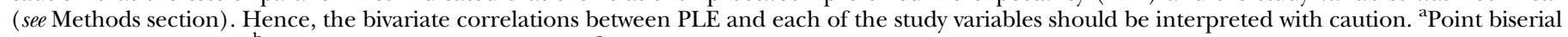
correlation coefficient; ${ }^{\text {}}$ Pearson correlation coefficient; ${ }^{\mathrm{c}}$ Phi correlation coefficient. SD: standard deviation: OAE: old age expectations.

Significance levels: $* p \leqslant 0.05, * * p \leqslant 0.01$. 
T А $\mathrm{L}$ E 3. Results of the multinomial regression analysis of preferred life expectancy

\begin{tabular}{|c|c|c|c|c|c|c|c|c|c|}
\hline \multirow[b]{2}{*}{ Preferred life expectancy } & \multicolumn{3}{|c|}{$\begin{array}{l}\text { Less than average life expectancy } \\
\qquad(<80 \text { years })\end{array}$} & \multicolumn{3}{|c|}{$\begin{array}{c}\text { Somewhat longer than average life } \\
\text { expectancy ( } 90-99 \text { years })\end{array}$} & \multicolumn{3}{|c|}{$\begin{array}{l}\text { Much longer than average life } \\
\text { expectancy (100+ years) }\end{array}$} \\
\hline & $B$ & SE $B$ & $\operatorname{Exp}(B)$ & $B$ & SE $B$ & $\operatorname{Exp}(B)$ & $B$ & SE $B$ & $\operatorname{Exp}(B)$ \\
\hline \multicolumn{10}{|l|}{ Old age expectations: } \\
\hline Positive & $-0.09^{*}$ & 0.04 & 0.91 & 0.08 & 0.04 & 1.08 & 0.08 & 0.04 & 1.08 \\
\hline Negative & 0.04 & 0.03 & 1.04 & $-0.07^{*}$ & 0.03 & 0.93 & $-0.07^{*}$ & 0.03 & 0.94 \\
\hline Age $\times$ positive & -0.01 & 0.00 & 0.99 & 0.00 & o.oo & 1.00 & o.OO & o.oO & 1.00 \\
\hline Age $\times$ negative & o.oo & 0.00 & 1.00 & 0.00 & 0.00 & 1.00 & $-0.01 * *$ & o.oo & 0.99 \\
\hline \multicolumn{10}{|l|}{ Control variables: } \\
\hline Age & -0.01 & 0.01 & 0.99 & 0.01 & 0.01 & 1.01 & 0.00 & 0.01 & 1.00 \\
\hline Gender (female) & -0.08 & 0.18 & 0.92 & 0.16 & 0.15 & 1.18 & 0.14 & 0.14 & 1.15 \\
\hline Education & -0.01 & 0.09 & 0.99 & 0.02 & 0.09 & 1.02 & 0.01 & 0.08 & 1.01 \\
\hline Income & $-0.11 * *$ & 0.04 & 0.89 & -0.04 & 0.04 & 0.96 & $-0.08^{*}$ & 0.04 & 0.92 \\
\hline \multicolumn{10}{|l|}{ Race/ethnicity: } \\
\hline Black & -0.03 & 0.26 & 0.97 & o.36 & 0.21 & 1.43 & $1.13^{* *}$ & 0.19 & 3.11 \\
\hline Hispanic & $0.61 * *$ & 0.24 & 1.83 & 0.01 & 0.22 & 1.01 & 0.29 & 0.21 & 1.33 \\
\hline Other & $0.92^{* *}$ & 0.33 & $2.5^{1}$ & $0.4^{1}$ & $0.3^{0}$ & $1.5^{1}$ & 0.17 & 0.34 & 1.19 \\
\hline Health & -0.01 & 0.11 & 0.99 & $0.24^{*}$ & 0.11 & 1.27 & $0.22 *$ & 0.10 & 1.24 \\
\hline \multicolumn{10}{|l|}{ Happiness: } \\
\hline Very happy & $-0.3^{2}$ & 0.23 & 0.73 & -0.08 & 0.17 & 0.92 & 0.29 & 0.16 & 1.34 \\
\hline Not too happy & $0.55^{*}$ & 0.23 & 1.73 & -0.10 & 0.25 & 0.91 & 0.20 & 0.22 & 1.22 \\
\hline Intercept & 0.59 & 0.59 & & $-1.73^{* *}$ & 0.59 & & -1.17 & 0.53 & \\
\hline
\end{tabular}

Notes: $\chi^{2}(42)=269.06, p<0.001$. Pseudo $R^{2}=0.15$ (Cox and Snell), 0.16 (Nagelkerke) and o.o6 (McFadden).

Significance levels: $* p \leqslant 0.05, * * p \leqslant 0.01$. 


\section{Catherine E. Bowen and Vegard Skirbekk}

\section{Discussion}

Little is known about how long people want to live, and even less is known about the factors associated with wanting to live a relatively short or long life. In the current study, we examined the extent to which longevity preferences were associated with positive and negative expectations about what one's own life in old age will be like using a large sample of younger and middle-aged adults in the USA. We statistically controlled for a range of variables empirically and theoretically linked to longevity preferences, including a number of socio-demographic characteristics, health and happiness. We examined whether the relationship between old age expectations and PLE depended on age. Since few studies have examined how younger adults perceive their own ageing, we also examined subjective positive and negative representations of one's own ageing and longevity preferences across four theoretically meaningful age groups.

\section{How long do people want to live?}

A study carried out more than 40 years ago (in 1970) in Los Angeles county revealed a median PLE of 80 years among those aged 20-59 and a median PLE of 88 years among those aged 6o+ (Kalish and Reynolds 1976). In the current study, median PLE was go years in our sample of adults aged 18-64. The results of the current study suggest that the preferred length of life may have increased somewhat in the last four decades and/or in more recent generations. We caution, however, that differences in the age and geographic coverage between our sample and the sample from Kalish and Reynolds (1976) (young and middle-aged adults versus young, middle and older adults; USA versus Los Angeles county, respectively) limit the comparability of the two studies.

All in all, the results of the current study suggest that a slight majority of younger and middle-aged adults in the USA would prefer to live beyond current levels of average life expectancy. More than a quarter of participants $(26.4 \%)$ indicated a preference to live at least 1 oo years. However, the current results also indicate that a significant minority of participants $(17.1 \%)$ do not seem to see historical increases in average life expectancy as a blessing and would prefer to die before they probably will based on estimates of average life expectancy. In other words, a significant minority seem to prefer the prospect of death over the prospect of living in old age. For many, it seems that the fear of becoming old may outweigh the fear of dying. 


\section{Non-response}

A substantial proportion $(15.9 \%)$ of the participants in the current study did not answer the PLE item. Published studies and surveys on PLE have not always included information about non-response. Lang, Baltes and Wagner (2007) reported relatively low levels of non-response among German participants asked to indicate either an age category or a specific age to which they would like to live (6.3 and $4.6 \%$, respectively). However, the rate of non-response was much larger when participants were explicitly given the option to answer 'I don't care' (20.2\%). In a recent representative study of adults in the USA, 9 per cent answered either 'Don't know' or 'Refused' (Pew Research Center 2013). In a representative study of 6o-year-olds in the USA, 25 per cent said they did not know or refused to answer (AARP 2006). Based on the available data, the rate of non-response in the current study does not seem unusual.

In the current study, older age, Black/African-American and Hispanic race/ethnicity, fewer negative and fewer positive old age expectations were significant predictors of non-response, though the model of non-response failed to correctly identify a substantial proportion of non-respondents. Only Lang, Baltes and Wagner (2007) reported the results of a missing data analysis on the PLE item. They found that non-response was related to older age and unemployment when PLE was measured with age categories. Reporting 'I don't know' was not related to age, gender, education, income, death of a parent or subjective health. Together, the missing data analyses from Lang, Baltes and Wagner (2007) and from the current study provide little evidence about the factors associated with PLE non-response. We therefore feel that predictors of non-response on the PLE item is an interesting question for future research. Potentially, the complexity, as opposed to the valence (positive/negative), of a person's subjective representations of ageing and old age may be a better predictor of non-response. We argue that people with more complex mental representations of their own old age are more likely to respond to the PLE item with it depends' or 'don't know', as they seem more likely to recognise that there is a great deal of uncertainty about how they will feel about their life at any particular age (i.e. there is no predictable age at which their life will suddenly become 'unliveable').

Fewer positive and more negative old age expectations related to preference for shorter lives

The results largely confirmed our hypotheses with regards to the relationship between old age expectations and longevity preferences. Our results 


\section{Catherine E. Bowen and Vegard Skirbekk}

also demonstrate that negative and positive old age expectations are differentially related to PLE. In the current study, having fewer positive old age expectations was associated with the preference for a relatively short life. In comparison, having fewer negative old age expectations was associated with preferring longer lives, especially for participants in late mid-life. The results therefore suggest that the preference to die young seems to be related to expecting few reasons for living, while the preference to live a very long time seems to be more related to expecting to have few reasons for wanting to die. Importantly, the relationships between negative and positive old age expectations and PLE were robust after statistically controlling for a range of variables based on the limited body of empirical evidence concerning correlates of longevity preferences. The current results offer more conclusive evidence on the effects of subjective representations of old age on longevity preferences (Levy, Ashman and Dror 2000; Levy et al. 2002; Marques et al. 2014) and extend findings to younger and middle-aged, healthy adults. Our results also add to the literature on how old age expectations shape how people approach their own development and ageing (e.g. Westerhof et al. 2014).

The significant interaction effect between negative old age expectations and age as a predictor of wanting to live 1 oo or more years (versus average life expectancy) is consistent with the 'self-relevance hypothesis', that images of old age become more important determinants of behaviour and self-perceptions with increasing age (e.g. Levy 20o9; Kornadt and Rothermund 2011,2012). Adults in late mid-life seem to be particularly sensitive to their negative expectations for old age relative to younger adults. Late mid-life adults may therefore particularly benefit from interventions that target their negative old age expectations. Interventions that help late mid-life adults to learn and implement strategies to avoid and/or cope with the potential negative aspects of ageing may reduce the effect that negative old age expectations seem to have on their overall desire to live a long life.

At least two studies have found that people who say that they want to live longer usually do (Huohvanainen et al. 2012 ; Karpinnen et al. 2012). In parallel, several studies have by now established that how people perceive and anticipate their own ageing process is associated with the extent to which people invest in maintaining and improving their health (Westerhof et al. 2014). For instance, older adults with more negative expectations for old age also find it less important to seek health care (Sarkisian, Hays and Mangione 2002). Older adults' old age expectations are also associated with their attitudes towards seeking mental health services (Kessler, Agines and Bowen 2015). Older and middle-aged adults with more negative old age expectations are less likely to engage in physical activity (Sarkisian 
et al. 2005; Wurm, Tomasik and Tesch-Römer 2010). Middle-aged and older adults with more negative old age expectations are also less likely to have received a complete physical examination in the previous two years (Meisner and Baker 2013). Based on previous research on the relationship between subjective representations of the ageing process/old age and health behaviour, we believe that health behaviour may explain at least part of the relationship between PLE and actual longevity. The current results suggest that people who anticipate more negative and fewer positive aspects of old age may invest less in their health because they do not want to live up to or beyond current levels of life expectancy and are hence reluctant to invest in behaviours that would lead to longer lives. Future research that directly tests this mediation hypothesis (i.e. old age expectations $\rightarrow$ PLE $\rightarrow$ health behaviour $\rightarrow$ actual longevity) would be useful.

\section{Subjective age representations and PLE among younger and middle-aged adults in the USA}

To date, few empirical studies have investigated how younger adults perceive and anticipate their own ageing. The descriptive statistics with regards to the old age expectations of the emerging and young adults in our sample thus add new information to the literature which can be used as a baseline for future research. Across each of the four age groups, participants indicated more positive than negative expectations for their own ageing. Our results also suggest that emerging and young adults in the USA are more optimistic about their own ageing than their older peers, as the weighted mean number of positive old age expectations was successively lower among the emerging, young, early mid-life and late mid-life participants. The pattern of negative old age expectations was somewhat less consistent, with young adults expressing the fewest negative expectations and late mid-life adults expressing the most negative expectations. When treating age as a continuous variable (versus age groups), younger age was related to having more positive expectations and fewer negative expectations for their own old age according to the bivariate correlations (see Table 2 ). Due to the cross-sectional nature of the data, we are unable to conclude if the age trends are due to generational or developmental differences. The median PLE and the distribution of PLE did not differ across four theoretically meaningful age groups included in our study, nor was age related to wanting to live shorter or longer than the average life expectancy. Thus, in contrast to findings from studies including older adults $\left(65^{+}\right)$ (Huohvanainen et al. 2012; Kalish and Reynolds 1976; Lang, Baltes and Wagner 2007; Pew Research Center 2013), age was not related to PLE in our sample of younger and middle-aged adults. 


\section{Differences in PLE associated with race}

Although not the main focus of the current study, we found it particularly interesting that, relative to all other race/ethnicity groups, more AfricanAmerican participants reported wanting to live 100 or more years. The high PLE of African-American participants is interesting in light of the fact that the objective life expectancy of African-Americans is lower relative to either Caucasian or Hispanic Americans (in 2009, life expectancy at birth was 74.3 years for African-Americans versus 78.7 and 81.1 years for Caucasian and Hispanic Americans, respectively; Centers for Disease Control and Prevention 2011). The relationship between race/ethnicity and PLE remained after accounting for education and income, indicating that race/ethnicity differences are not explained by differences in socioeconomic status. The high PLE of African-American participants in the current study is consistent with the findings of Kalish and Reynolds $(1976)$, who found that the average PLE of African-American respondents was more than eight years higher than any of the other ethnic groups in the sample. The strong association between Black/African-American race and a desire to live a very long life in the current study is also consistent with related findings from time trade-off tasks (Ayalon and King-Kallimanis 2010) and end-of-life practices (Barnato et al. 2009). We feel that the consistent and unexplained findings with regards to race and longevity preferences warrant further research.

\section{Health, happiness, income, gender and education}

In line with previous studies on longevity preferences and related constructs (Ayalon and King-Kallimanis 2010; Huohvanainen et al. 2012; Jopp, Rott and Oswald 2008; Lang, Baltes and Wagner 2007), 'not being too happy' was related to the preference to die before reaching average life expectancy, and better self-rated health was related to wanting to live longer than average life expectancy. Self-rated health was not, however, related to the preference to die younger than the average life expectancy. This pattern of results suggests that young and middle-aged participants with worse current health still seem to prefer to at least average life expectancy but do not strive to attain any additional years.

Lower income distinguished both people who indicated a preference for a short and a very long life. We find this seemingly paradoxical result intriguing and worthy of future research. Income is likely related to longevity preferences through several mechanisms. On the one hand, people with lower income may feel less prepared to cope financially with age-related challenges (e.g. illness) and may thus prefer shorter lives. On the other 
hand, people with lower income may define themselves less in terms of their ability to earn money through paid work, or may have less satisfying jobs. In turn, people with lower income may be more optimistic about the prospect of more post-retirement life years.

Neither gender nor education was related to longevity preferences in the current study, despite the fact that women and people with a higher educational background tend to live longer than men and people with a lower educational background, respectively. The non-relationship between gender and PLE observed in the current study diverges from previous research (Ayalon and King-Kallimanis 2010; Carmel 2001; Carmel, Shrira and Shmotkin 2013; Dragojlovic 2013; Kalish and Reynolds 1976). The difference in results may be due to methodological differences between the studies (e.g. sample characteristics like nationality or age, indicator of longevity preference). The current results may also point to a shift in gender differences across historical time ( $c f$. Kalish and Reynolds 1976).

\section{Limitations}

The current results should be viewed in the light of a number of important limitations. The PLE measure is a single item which provides an indication of how long people generally want to live, all things considered. The advantages of the PLE measure include that it is straightforward and that answers are directly comparable across people and groups since the scale (life years) is not dependent on subjective interpretations. The limitations of the measure include that it does not assess more complex, subtle or implicit (i.e. below the level of consciousness) preferences, nor how people would think or behave when actually confronted with death. The rather crude measurement of the age expectation items (yes/no) represents a further limitation of the current study. Future studies with more elaborate measurements of age expectations would be helpful (e.g. items with a greater range of answer possibilities). The cross-sectional nature of the data implies some ambiguity with regards to the directionality and/or causality of the relationships between PLE and the predictor variables. Furthermore, in the current study we investigated the average relationships between PLE and old age expectations. Future studies that test specific, theory-driven interactions between personal characteristics and specific age expectations (e.g. current income and expectations about financial security, current loneliness and expectations about loneliness) would therefore be helpful. In addition, cross-sectional and longitudinal studies of the relationship between how long people want to live and health behaviours such as seeking professional health care and engaging in physical exercise would be worthwhile given the association between representations of age and health behaviours (see above). 
Limitations notwithstanding, the results of the current study offer new insights and raise new questions with regards to PLE and with regards to the effects of common old age expectations. The current study represents a first look at which factors beyond basic socio-demographic characteristics, health and wellbeing underlie individual differences in longevity preferences. The large and diverse sample as well as the inclusion of emerging and young adults represent major strengths of the study. The current results suggest that bleak expectations of what life will be like in old age can undermine the desire to live to current levels of average life expectancy and beyond. Adults in late mid-life seem to be particularly sensitive to their negative expectations for old age relative to younger adults. In light of our results, we feel it is important to recognise that people who embrace the 'better to die young' attitude, such as Dr Ezekiel Emanuel in his declaration that he only wants to live to 75 in a recent edition of The Atlantic (Emanuel 2014), may potentially underestimate their ability to cope successfully with the negative age-related life experiences as well as to find new sources of wellbeing in old age. In fact, contrary to common stereotypes, empirical studies indicate that wellbeing is in fact remarkably stable across much of the adult lifespan (e.g. Scheibe and Carstensen 2010). We believe that additional research on the factors underlying why some people want to live very long lives and others would prefer to die relatively young would be fruitful as societies and individuals are confronted with longer lives.

\section{Acknowledgements}

This work was supported by a Starting Grant of the European Research Council, Grant Agreement 241003-COHORT awarded to the second author. The sponsors played no role in the design, execution, analysis and interpretation of data, or the writing of the study. Catherine E. Bowen contributed to the conception of the study, conducted the statistical analysis and drafted the article. Vegard Skirbekk contributed to the conception of the study and revised the manuscript. The authors declare no conflict of interest. The current study is based on secondary data analysis of publicly available data. Ethical approval was therefore not required.

\section{References}

American Association of Retired Persons (AARP) 2006. Boomers Turning 6o. Available online at http://assets.aarp.org/rgcenter/general/boomers6o.pdf [Accessed 28 January 2015].

American Association of Retired Persons (AARP) 2010. Approaching 65: A Survey of Baby Boomers Turning ${ }_{5}$ Years Old. Available online at http://assets.aarp.org/ rgcenter/general/approaching-65.pdf [Accessed 28 January 2015]. 
Arnett, J. J. 200o. Emerging adulthood: a theory of development from the late teens through the twenties. American Psychologist, 55, 5, 469-80.

Ayalon, L. and King-Kallimanis, B. L. 2010. Trading years for perfect health: results from the Health and Retirement Study. Journal of Aging and Health, 2 2, 8, 11 84-97.

Barnato, A. E., Anthony, D. L., Skinner, J., Gallagher, P. M. and Fisher, E. S. 2009. Racial and ethnic differences in preferences for end-of-life treatment. Journal of General Internal Medicine, 24, 6, 695-701.

Becker, E. 1973. The Denial of Death. Simon \& Schuster, New York.

Carmel, S. 2001. The will to live: gender differences among elderly persons. Social Science $\mathcal{E}$ Medicine, 52, 6, 949-58.

Carmel, S., Shrira, A. and Shmotkin, D. 2013. The will to live and death-related decline in life satisfaction. Psychology and Aging, 28, 4, $1115^{-23}$.

Centers for Disease Control and Prevention 201 1. Table 22. Life Expectancy at Birth, at Age 65, and at Age 75, By Sex, Race, and Hispanic Origin: United States, Selected Years I90o-20Io. Available online at http://www.cdc.gov/nchs/data/hus/2011/022. pdf [Accessed 28 January 2015 ].

Cuddy, A. J., Norton, M. I. and Fiske, S. T. 2005. This old stereotype: the pervasiveness and persistence of the elderly stereotype. Journal of Social Issues, 6 1, 2, 267-85.

Dragojlovic, N. 2013. Canadians' support for radical life extension resulting from advances in regenerative medicine. Journal of Aging Studies, 27, 2, 151-8.

Elo, I. T. 2009. Social class differentials in health and mortality: patterns and explanations in comparative perspective. Annual Review of Sociology, 35, 1, 553-72.

Emanuel, E. J. 2014. Why I hope to die at 75. The Atlantic, October. Available online at http://www.theatlantic.com/features/archive/2014/og/why-i-hope-to-die-at75/379329/ [Accessed 28 January 2015].

Freud, S. 1920. Beyond the Pleasure Principle. International Psycho-Analytical Press, London.

Gottschall, A. C., West, S. G. and Enders, C. K. 201 2. A comparison of item-level and scale-level multiple imputation for questionnaire batteries. Multivariate Behavioral Research, 47, 1, 1-25.

Graham, J. W. 20o9. Missing data analysis: making it work in the real world. Annual Review of Psychology, 6o, 1, 549-76.

Heckhausen, J., Dixon, R. A. and Baltes, P. B. 1989. Gains and losses in development throughout adulthood as perceived by different adult age groups. Developmental Psychology, 25, 1, 109-21.

Huohvanainen, E. A., Strandberg, T. E., Pitkälä, K. H., Karppinen, H. and Tilvis, R. S. 2012. Do you wish to live to the age of 100? A survey of older men. Journal of the American Geriatrics Society, 6o, 10, 1983-4.

Jopp, D., Rott, C. and Oswald, F. 20o8. Valuation of life in old and very old age: the role of sociodemographic, social, and health resources for positive adaptation. The Gerontologist, 48, $5,64^{6-} 5^{8 .}$

Kalish, R. A. and Reynolds, D. K. 1976. Death and Ethnicity: A Psychocultural Study. The University of Southern California Press, Los Angeles.

Karppinen, H., Laakkonen, M.-L., Strandberg, T. E., Tilvis, R. S. and Pitkala, K. H. 2012. Will-to-live and survival in a 1o-year follow-up among older people. Age and Ageing, 41, 6, 789-94.

Kessler, E.-M., Agines, S. and Bowen, C. E. 2015 . Attitudes towards seeking mental health services among older adults: personal and contextual correlates. Aging $\mathcal{E}^{\circ}$ Mental Health, 19, 2, 182-91.

Kibele, E. U. B., Jasilionis, D. and Shkolnikov, V. M. 2013. Widening socioeconomic differences in mortality among men aged $6_{5}$ years and older in Germany. Journal of Epidemiology E Community Health, 67, 5, 453-7. 


\section{Catherine E. Bowen and Vegard Skirbekk}

Kite, M. E., Stockdale, G. D., Whitley, B. E. and Johnson, B. T. 2005. Attitudes toward younger and older adults: an updated meta-analytic review. Journal of Social Issues, 61, 2, 241-66.

Knesebeck, O. V. D., Wahrendorf, M., Hyde, M. and Siegrist, J. 2007. Socio-economic position and quality of life among older people in 10 European countries: results of the SHARE study. Ageing $\mathcal{E} \mathcal{F}$ Society, 27, 2, 269-84.

Kornadt, A. E. and Rothermund, K. 2011 . Contexts of aging: assessing evaluative age stereotypes in different life domains. Journals of Gerontology: Psychological Sciences and Social Sciences, 66B, 5, 547-56.

Kornadt, A. E. and Rothermund, K. 2012 . Internalization of age stereotypes into the self-concept via future self-views: a general model and domain-specific differences. Psychology and Aging, 27, 1, 164-72.

Lang, F. R., Baltes, P. B. and Wagner, G. G. 2007. Desired lifetime and end-of-life desires across adulthood from 20 to 9o: a dual-source information model. Journals of Gerontology: Psychological Sciences and Social Sciences, 62B, 5, 268-76.

Lawton, M. P., Moss, M., Hoffman, C., Grant, R., Ten Have, T. and Kleban, M. H. 1999. Health, valuation of life, and the wish to live. The Gerontologist, 39, 4, 4o6-16.

Lawton, M. P., Moss, M., Hoffman., C., Kleban, M. H., Ruckdeschel, K. and Winter, L. 2001. Valuation of life: a concept and a scale. Journal of Aging and Health, 13, 1, 3-31.

Levy, B. 2009. Stereotype embodiment: a psychosocial approach to aging. Current Directions in Psychological Science, 18, 6, 332-6.

Levy, B., Ashman, O. and Dror, I. 200o. To be or not to be: the effects of aging stereotypes on the will to live. Omega - Journal of Death and Dying, 4o, 3, 409-20.

Levy, B., Slade, M. D., Kunkel, S. R. and Kasl, S. V. 2002. Longevity increased by positive self-perceptions of aging. Journal of Personality and Social Psychology, 83, 2, 261-70.

Marques, S., Lima, M.-L., Abrams, D. and Swift, H.J. 2014. Will-to-live in older people's medical decisions: immediate and delayed effects of aging stereotypes. Journal of Applied Social Psychology, 44, 6, 399-408.

Meisner, B. A. and Baker, J. 2013. An exploratory analysis of aging expectations and health care behavior among aging adults. Psychology and Aging, 28, 1, 99-104.

Nielsen, L., Knutson, B. and Carstensen, L. L. 2008. Affect dynamics, affective forecasting, and aging. Emotion, 8, 3, 318-30.

O'Connell, A. 2011 . How long do we expect to live? A review of the evidence. Journal of Population Ageing, 4, 3, $185^{-201 .}$

Olshansky, S.J., Antonucci, T., Berkman, L., Binstock, R. H., Boersch-Supan, A., Cacioppo, J. T., Carnes, B. A., Carstensen, L. L., Fried, L. P., Goldman, D. P., Jackson, J., Kohli, M., Rother, J., Zheng, Y. and Rowe, J. 201 2. Differences in life expectancy due to race and educational differences are widening, and many may not catch up. Health Affairs, 31, 8, 1803-13.

Pew Research Center 2009. Growing Old in America: Expectations vs. Reality. Available online at http://www.pewsocialtrends.org/files/2010/10/Getting-Old-in-America. pdf [Accessed 28 January 2015].

Pew Research Center 2010. 2009 Aging Survey [data file]. Available online at http:// www.pewsocialtrends.org/category/datasets/2010/ [Accessed 28 January 2015].

Pew Research Center 2013. Living to I 20 and Beyond: Americans' Views on Aging, Medical Advances and Radical Life Extension. Available online at http://www.pewforum.org/ files/2013/o8/Radical-life-extension-full.pdf [Accessed 28 January 2015].

Rosenmayr, L. 1983. Die späte Freiheit: das Alter, ein Stück bewusst gelebten Lebens [Late Freedom]. Severin und Siedler, Berlin.

Russac, R. J., Gatliff, C., Reece, M. and Spottswood, D. 2007. Death anxiety across the adult years: an examination of age and gender effects. Death Studies, 31, 6, 549-61. 
Sarkisian, C. A., Hays, R. D. and Mangione, C. M. 2002. Do older adults expect to age successfully? The association between expectations regarding aging and beliefs regarding healthcare seeking among older adults. Journal of the American Geriatrics Society, 5o, 1 1, 1837-43.

Sarkisian, C. A., Prohaska, T. R., Wong, M. D., Hirsch, S. and Mangione, C. M. 2005. The relationship between expectations for aging and physical activity among older adults. Journal of General Internal Medicine, 2o, 10, 91 1-15.

Scheibe, S. and Carstensen, L. L. 2010. Emotional aging: recent findings and future trends. Journals of Gerontology: Psychological Sciences and Social Sciences, 65 B, 2, 135-44.

Social Security Administration n.d. Life Tables. Available online at http://www.ssa. gov/oact/STATS/table 4c6.html [Accessed 28 January 2015].

Staudinger, U. M. and Bluck, S. 2001. A view on midlife development from lifespan theory. In Lachman, M. E. (ed.), Handbook of Midlife Development. Wiley, New York, 3-39.

Steverink, N., Westerhof, G. J., Bode, C. and Dittmann-Kohli, F. 2001. The personal experience of aging, individual resources, and subjective well-being. Journals of Gerontology: Psychological Sciences and Social Sciences, 56B, 6, 364-73.

Trope, Y. and Liberman, N. 2010. Construal-level theory of psychological distance. Psychological Review, 11 7, 2, 440-63.

United Nations, Department of Economic and Social Affairs, Population Division 2015. World Population Prospects: The 2015 Revision. Available online at http:// esa.un.org/unpd/wpp/Download/Standard/Mortality/ [Accessed 8 May 2016].

Vernon, G. M. 1972. Death control. Omega - Journal of Death and Dying, 3, 2, 131-8.

Westerhof, G. J., Miche, M., Brothers, A. F., Barrett, A. E., Diehl, M., Montepare, J. M., Wahl, H.-W. and Wurm, S. 2014. The influence of subjective aging on health and longevity: a meta-analysis of longitudinal data. Psychology and Aging, 29, 4, $793^{-802 .}$

Wilson, T. D. and Gilbert, D. T. 2005. Affective forecasting. Knowing what to want. Current Directions in Psychological Science, 14, 3, 131-4.

Wong, P. T. P., Reker, G. T. and Gesser, G. 1994. Death Attitude Profile - revised: a multidimensional measure of attitudes toward death. In Neimeyer, R. A. (ed.), Death Anxiety Handbook: Research, Instrumentation, and Application. Taylor \& Francis, Washington DC, $121-48$.

Wurm, S., Tomasik, M.J. and Tesch-Römer, C. 2010 . On the importance of a positive view on ageing for physical exercise among middle-aged and older adults: crosssectional and longitudinal findings. Psychology $\mathcal{E}^{2}$ Health, 25, 1, 25-42.

Accepted I 2 May 2016; first published online I 5 July 2016

Address for correspondence:

Catherine E. Bowen,

Wittgenstein Centre for Demography and Global Human Capital, Vienna Institute of Demography/Austrian Academy of Sciences, Welthandelsplatz 2/Level 2, 1020 Vienna, Austria

E-mail: Catherine.Bowen@oeaw.ac.at 